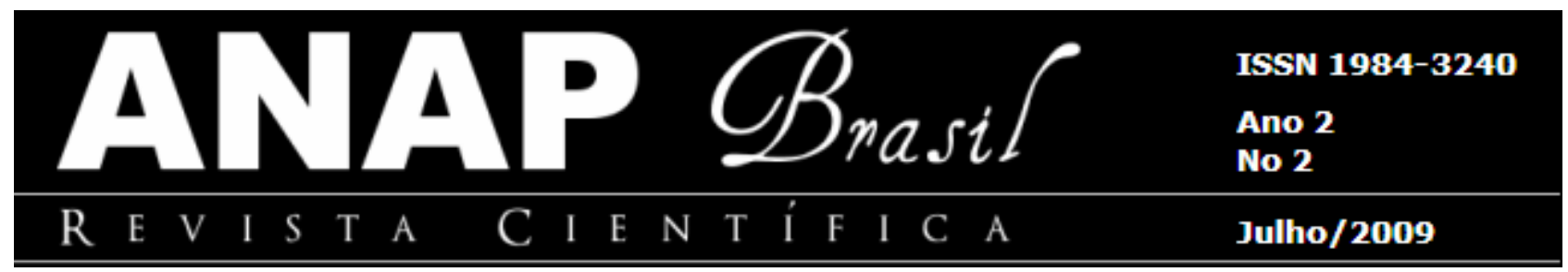

\title{
O PENSAMENTO DE EDGAR MORIN E A GEOGRAFIA DA COMPLEXIDADE
}

\author{
Maria Betânia Moreira Amador*
}

Resumo: Este trabalho é resultado de pesquisa tanto para a tese de doutorado concluída em 2008 sobre a contribuição da visão sistêmica ao estudo do espaço agrário, quanto para a elaboração de mini-curso ministrado por ocasião da VIII Semana Universitária na Faculdade de Ciências, Educação e Tecnologia de Garanhuns/UPE. O principal objetivo é trazer à tona um pouco da biografia de Edgar Morin no que tange ao seu envolvimento com a Teoria da Complexidade, especialmente voltado para um público que fala de Morin, da teoria, mas que não faz idéia, ou faz pouca, de quem se trata e da sua trajetória de vida até seu consagramento. Outro ponto importante, e o artigo segue essa estrutura, é mostrar que conteúdos vivenciados para se produzir pesquisas, como encontrados na Metodologia Científica, tem sua importância vital para o encadeamento das idéias e para o desfecho que se quis dar ao se contemplar a Geografia da Complexidade. Deixa transparecer, também, embora nas entrelinhas, que a complexidade, o sistemismo estão, desde longa data, imbricados com a Geografia e que ela é uma das ciências que tem muito a contribuir com as causas ambientais.Para esse intento procedeu-se ao levantamento bibliográfico, prioritariamente, como metodologia de trabalho, julgando-se que os resultados, embora não empíricos e não fisicamente presentes, possam ser motivadores para aqueles que se dedicarem a sua leitura e, principalmente, os que avançarem além do que aqui foi, singelamente, disponibilizado. A conclusão que se apresenta é que se deve pensar a Geografia através de geógrafos, licenciados e/ou bacharéis com mais sensibilidade e mais amor, esperando-se contribuir para um mundo melhor.

Palavras-chave: Edgar Morin; Complexidade; Geografia 


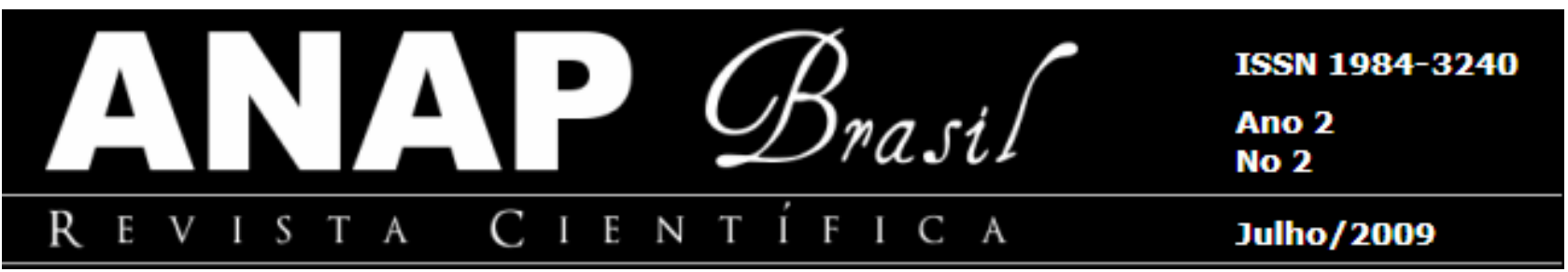

*Prof ${ }^{a}$ Drํa em Geografia, Faculdade de Ciência, Educação e Tecnologia de Garanhuns FACETEG/Universidade de Pernambuco - UPE. betaniaamador@yahoo.com.br

\section{INTRODUÇÃO}

O objetivo primordial deste trabalho é associar o pensamento de Edgar Morin às idéias que perpassam o sistemismo, o qual se tem a impressão que se encontra em franca ascensão enquanto escolha teórica no âmbito da Geografia, e que se cristaliza na chamada "Geografia da Complexidade".

Ademais, julga-se de interesse iniciar o texto com um breve resgate biográfico de Edgar Morin na intenção de situar, prioritariamente, os novatos da pesquisa que, no cotidiano acadêmico de seus vários cursos de graduação e pós-graduação, não tenham tido a oportunidade de se debruçar mais amiúde sobre a vida e obra deste pensador que muito contribuiu, nesses últimos anos para revolucionar a forma de pensar e agir, tanto da educação em si quanto de políticas de formação e atuação de profissionais de diversas áreas do conhecimento que precisam ter uma visão integrada da realidade a fim de minimizar os impactos ambientais inerentes a cada uma de suas atuações profissionais.

A biografia de qualquer vulto ilustre ajuda a entender, entre outras coisas, a razão do porque da escolha feita e evidencia muito frequentemente, o caminho de espinhos ou rosas trilhado por essa pessoa chegando à sua contribuição inquestionável deixada para a sociedade.

É nesse sentido que se quer trabalhar as idéias morinianas tentando, dentro do possível, associá-las à Geografia, mas uma Geografia integrada e integradora, uma Geografia que busca entender o espaço não só por ele mesmo, mas também e principalmente pelas ações antrópicas que se impõe a esse espaço através de uma sociedade ora consciente, ora inconsciente de suas ações.

Ou seja, a complexidade não visa apenas o materialismo, não é só ver para crer, pesar e medir, não busca a simplicidade da causa-efeito, evidencia o metafísico presente no universo, na mente humana, no respeito aos valores de ordens diversas sem esquecer 


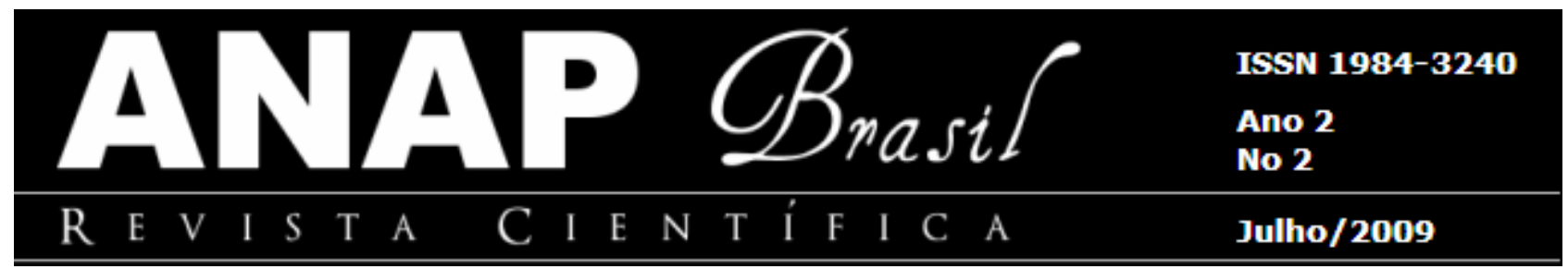

os animais, e outros elementos viventes ou não, críveis ou não, porém todos constituintes do mundo em que vivemos buscando-se entendimentos e possíveis soluções a partir da recursividade e integração dos fenômenos.

\section{BREVE BIOGRAFIA}

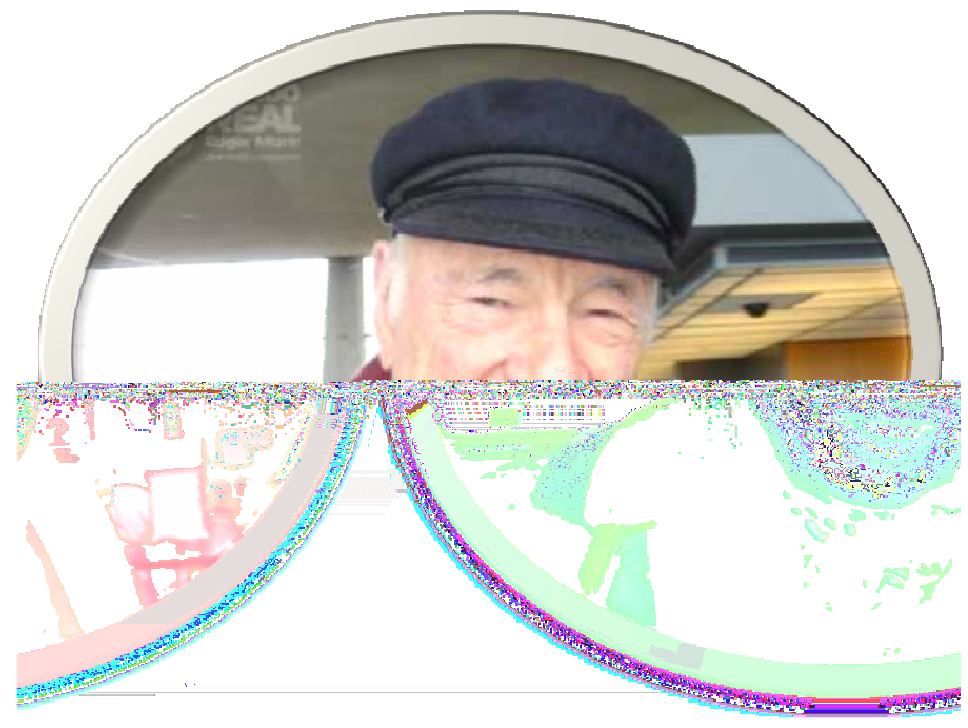

Fonte: file://K:IEdgar Morinlfoto edgar morin 2.mht

Edgar Morin, cujo nome verdadeiro é Edgar Nahoun, nasceu em 1921 na França. Filho único de um casal de origem judia graduou-se em História, Geografia e Direito o que Ihe proporcionou embasamento para desenvolver estudos em Sociologia, Filosofia e Economia (GENTILE, 2003, p.1), integrando-se aos poucos à problemática educacional, área que vem Ihe atribuindo grande significância pelas contribuições para a reforma do pensamento e do ensino.

No entanto, é pertinente colocar que Morin teve sua vida imbricada com alguns momentos de guerras históricas, entre elas a Guerra Civil Espanhola. Nesta, Morin teve sua performance política reconhecida por ele mesmo quando participou entre os anos de 


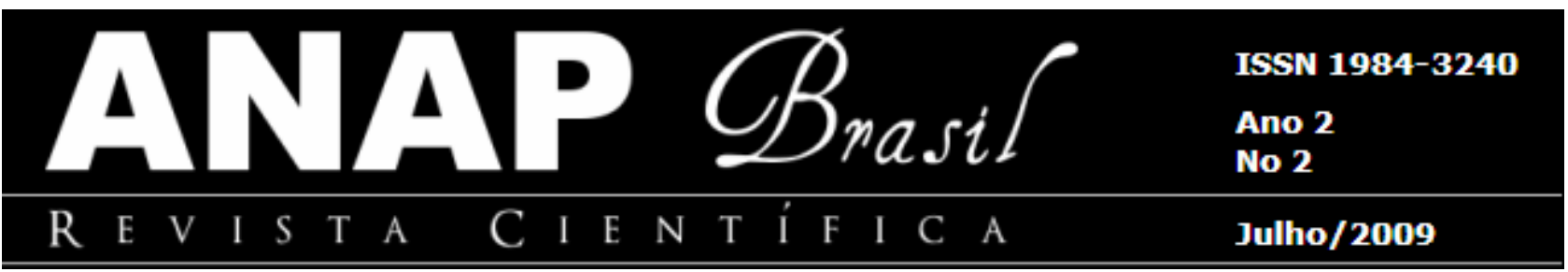

1936-37 da Frente Popular, movimento que atuava em prol dos chamados anarquistas catalãs. Como militante atuante, muito jovem e entusiasmado participou de seu primeiro comício político, cujo teor das palavras se respaldava no ideal trotskista (SESC, 2008, p.1).

Nos anos de 1938-39, com os indícios de uma grande guerra se avolumando, Edgar Nahoun se junta ao movimento dos Estudantes Frentistas os quais preconizavam um socialismo nacional e a rejeição à guerra. Nesse grupo havia um professor de Filosofia que o introduziu aos estudos marxistas. Nesse momento, Morin se encontrava realizando seus estudos na Sorbonne quando, em 1940-41 teve que interromper seus exames devido ao fato da França ter sido invadida pelos alemães.

Para escapar da situação, vai morar em Toulouse onde faz amizades com refugiados e passa a prestar assistencialismo assumindo o cargo de secretário dos Estudantes Refugiados. Ao mesmo tempo em que freqüenta com assiduidade a Biblioteca Municipal se deparando e lendo com os grandes clássicos disponíveis no recinto.

Em 1941-42, então, ajuda o escritor Julien Brenda fazendo anotações para o mesmo. Esse escritor o instiga a se aprofundar na leitura de obras importantes, passa a ter aulas sobre Filosofia da Existência, a conhecer a obra de Hegel. Consequentemente, o seu veio político o impulsiona a fazer grafitagem e panfletagem e a se filiar ao Partido Comunista.

Em julho de 1942, foge para Lyon devido invasão do exército alemão e, por estar cada vez mais envolvido com atividades subversivas, toma a decisão de substituir o sobrenome Nahoun por Morin. A partir daí, sua vida se reveste de dupla clandestinidade, ou seja, não pode se mostrar publicamente como judeu e comunista, além de atuar na Resistência Francesa (SESC, 2008, p.2).

Assim, cada vez mais se sentindo acuado pela GESTAPO (Polícia Secreta Alemã), foge para Toulouse onde é abrigado por uma família de operários e lá, organiza uma célula clandestina junto com um amigo. O amigo é preso, torturado e morto por essa polícia secreta. Morin então regressa a Paris onde participa ativamente da Resistência coincidindo com a Insurreição de Paris em agosto de 1944.

Em 1945 é nomeado Tenente-Coronel e incorporado ao governo militar da zona francesa de ocupação. Permanece no Partido Comunista Francês até ser expulso. Sua 


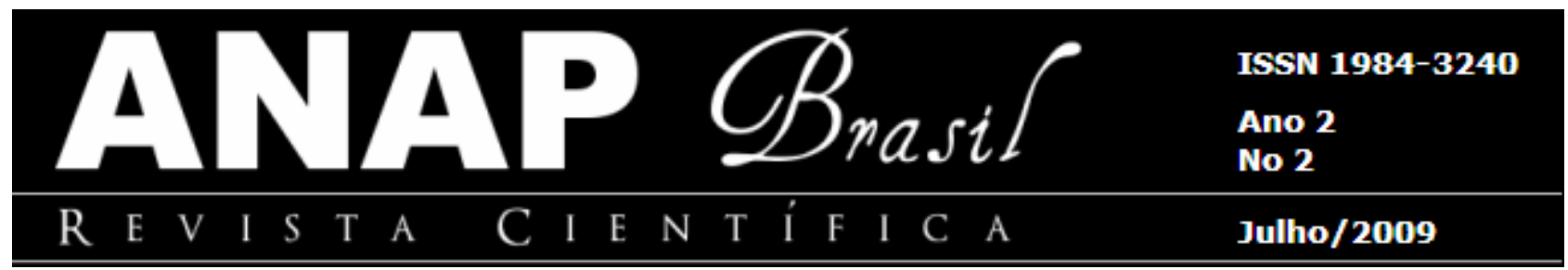

expulsão se deu devido seu espírito crítico e alto poder reflexivo. Discordava de questões essenciais que o levaram a denunciar desvios e excessos do estalinismo soviético e a criticar outros sistemas comunistas existentes à época. Então passa a trabalhar em jornais ligados ao Partido Comunista como redator, mas é tratado com desconfiança. Em 1946 dá baixa do exército francês.

Nos anos 1948 - 49, Edgar Morin passa um período sem emprego e sendo cada vez mais relegado dentro do Partido Comunista, fato que o leva a se exilar dentro de si mesmo. Nesse momento escreve o livro "O Homem e a Morte", essa obra torna-se importante porque é nela que ele traça a base de sua cultura transdisciplinar passando pela Geografia Humana; Pré-História; Psicologia infantil; Psicanálise, História das Religiões, Ciência das Mitologias entre outras.

O Homem e a Morte - integrando seu pensar marxista às concepções de Freud, Lacan, Jung e outros, Morin trabalha a idéia da morte como fenômeno capaz de distiguir o humano da máquina. É frente a ela que o homem define para si o que Ihe é mais importante. Reflete sobre a organização vital, reorganizada continuamente, e explica a distinção que faz do homem frente a outros seres pelo utensílio (Homo faber), pelo cérebro (Homo sapiens) e pela linguagem (Homo loquax).Ë o que permite observar a evolução das idéias do autor (UNINOVE, 2008, p. 2).

No prosseguimento do rumo de sua vida, entre os anos de 1951-52, candidata-se ao CNRS (Centro Nacional de Estudos de Pesquisa Científica), entre as cartas de recomendação encontra-se a de Pierre George, eminente geógrafo francês, Morin então é contratado como estagiário de pesquisas. Nesse Centro, escolhe como tema de pesquisa a sociologia do cinema e, apesar de algumas investidas cinemátográficas desiste de fazer cinema em torno de 1960, permanecendo na sua produção literária.

Importante salientar, ainda que, em 1961 Edgar Morin faz uma longa viagem pela América Latina, inclusive o Brasil. Momento em que conheceu de perto a cultura indígena e o mundo afro-brasileiro. Ao retornar para a França publica o livro intitulado "O Espírito do Tempo" (SESC, 2008, p.3).

No Centro de Pesquisas e de Estudos Sociais e Políticos - CRESP, nos anos de 1963-64, se junta a dois outros grandes nomes: Lefort e Castoriades, os quais aspiram um pensamento que pudesse dar conta da invenção, da criação e do sujeito e assim, passa a escrever artigos para o Jornal Le Monde. 


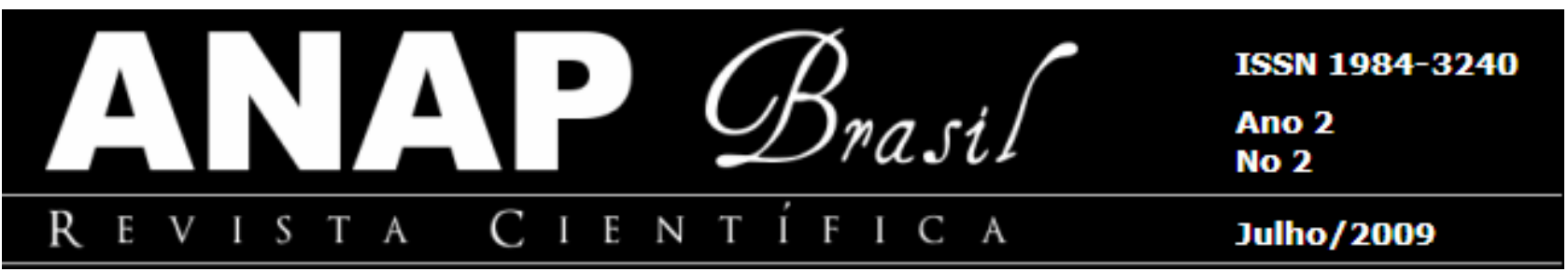

Em 1967 é convidado a participar do Grupo dos Dez, onde se aprofunda na Biologia e descobre o pensamento cibernético. No ano seguinte, Morin substitui Henri Lefebvre na Universidade de Nanterre e, mais uma vez, se envolve politicamente na França quando eclodem nesse país as revoltas estudantis. Morin, então, escreve no Le Monde artigos onde tenta compreender o sentido daquilo que chamou de "a comuna estudantil". Nesse meio tempo veio ao Brasil ministrar cursos nas universidades de Rio e São Paulo e sempre era recebido por delegações de estudantes, pois aqui também se tinha um clima de protestos.

Em seguida, na passagem para os anos setenta, passa um ano na Universidade da Califórnia onde apreende conhecimentos da biologia genética. A partir daí, inicia-se nas "três teorias" que considera interpenetrantes e inseparáveis, quais sejam: a cibernética, a teoria dos sistemas e a teoria da informação.

De volta a Paris, organiza a constituição de um centro internacional de estudos bioantropológicos e de antropologia fundamental. Nele realizar-se-iam vários encontros inter e transdisciplinares, os quais deram vez a um grande seminário internacional sobre a Unidade do Homem. Após um breve período, desliga-se dessa instituição e mergulha no conhecimento da teoria da auto-organização.

Toda essa experiência de vida e profissional deu a Morin condições de elaborar o primeiro, de uma coleção de 6 livros, chamado "O Método - a natureza da natureza", obra fundamental para se entender o que ele defende por complexidade.

Ao longo dos anos, segue sua trajetória produtiva, e ao que se sabe até o presente, continua atuante. O pensamento complexo é sua marca registrada se coadunando com as novas investidas da Ciência em abrir espaço para os que "pensam complexo" e, não apenas somente do ponto de vista reducionista. Assim pensar complexamente requer um método:

O método do pensamento complexo é a ativação de princípios anti-cartesianos e pós-cartesianos, no sentido de que não rejeita os resultados da ciência reducionista, mas descobre a possibilidade de recusar as suas limitações, no que concerne, pelo menos, à modelização dos problemas propostos (PENAVEGA; ALMEIDA, 1999, p. 125). 


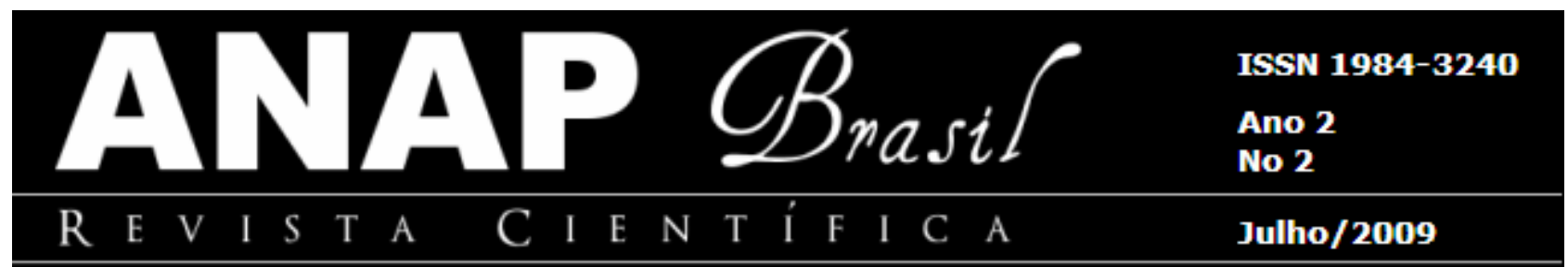

Morin entende que o pensamento complexo é um tipo de pensamento que não separa, mas une e busca as relações necessárias e interdependentes de todos os aspectos da vida.

\section{TEORIA DA COMPLEXIDADE}

* Uma Teoria? O que é mesmo uma teoria?

* Um Pensamento? E o que se entende por um pensamento no contexto da ciência?

* Um Paradigma? Qual o seu conceito? Em que situação se aplica?

* Um Método? O que é e para que serve um método?

TEORIA

Com base em algumas leituras, principalmente Köche (1997, p.90 - 91) e Lakatos; Marconi (2003, p. 114), admite-se ser a síntese das leis particulares ligadas por uma explicação comum. Tem um caráter explicativo mais universal do que a lei.

- As teorias dão um quadro coerente dos fatos conhecidos, indicam como são organizados e estruturados, explicam-nos, provem-nos e fornecem-nos pontos de referência para observação de novos fatos.

- $\quad$ a $L E I$ ? Como se encaixa na teoria?

Tanto a lei quanto a teoria surgem da necessidade de se ter que encontrar explicações para o fenômeno da realidade.

Pode-se, então, apreender que a Lei é a comparação científica da relação causa e efeito, principalmente sob a ótica reducionista.

"A era que virá há de nos mostrar o caos por trás da lei". J. A. Wheeler apud (MORIN 2001, p. 95).

Em A cabeça bem - feita, Morin expõe sua preocupação com o pensamento reinante, o qual respalda todo um contexto educacional e que precisa ser pensado, repensado e reformulado. Morin se vale de Montaigne para refletir sobre esse tema: "Mais vale uma cabeça bem-feita que bem cheia"; defende que na cabeça bem cheia o saber é 


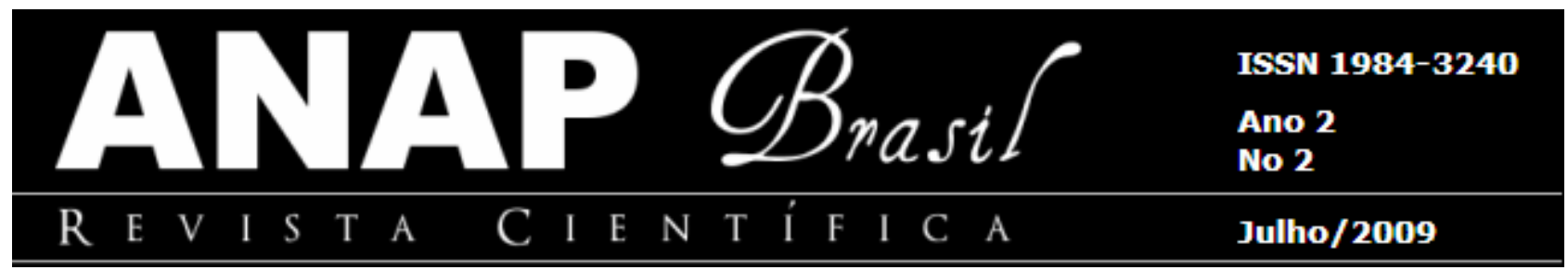

acumulado, empilhado, e não dispõe de um princípio de seleção e organização que lhe dê sentido, assim a frase que se segue ilustra bem esse problema: "Sei tudo, mas não compreendo nada”. René Daumai apud (MORIN, 2001, p. 87). Na cabeça bem - feita em vez de acumular o saber, é mais importante dispor ao mesmo tempo de: a) uma aptidão para colocar e tratar os problemas; b) princípios organizadores que permitam ligar os saberes e lhes dar sentido. Trata-se, portanto, de encorajar desde cedo a curiosidade e a investigação, orientando-os para os problemas fundamentais de nossa época. Em sequência, expõe-se a seguinte máxima para reflexão: "Eu creio pessoalmente que há pelo menos um problema... que interessa a todos os homens que pensam: o problema de compreender o mundo, nós mesmos e nosso conhecimento como parte do mundo". Karl Popper apud (MORIN, 2003, p.21).

O pensamento complexo é o pensamento que se esforça para unir, não de forma confusa, mas operando diferenciações. Para isso é necessário conhecimento porque a contextualização do problema ou do fenômeno exige sua inserção num quadro mais abrangente. Ex. Obras de engenharia; entendimentos de problemas de saúde, entre outros. Contextualizar é, portanto, realizar operações lógicas contrárias às de disjunção e redução, contrárias às operações de simplificação que produzem uma simplicidade atomizada (VASCONCELLOS, 2006,113).

\section{PENSAMENTO}

O pensamento é uma atividade do espírito humano que, como qualquer atividade do espírito, expande-se na esfera da linguagem, da lógica e da consciência, comportando, como toda atividade do espírito, processos sublinguísticos e subconscientes. E, de acordo com Chauí (2002. p.153):

O pensamento exprime nossa existência como seres racionais e capazes de conhecimento abstrato e intelectual e, sobretudo manifesta sua própria capacidade para dar a si mesmo leis, normas, regras e princípios para alcançar a verdade de alguma coisa.

E aqui entra o fator cultura, pois a sociedade, na qual se insere o sujeito tem sua cultura com seu conjunto de valores e paradigmas que norteiam o rumo da vida dessa 


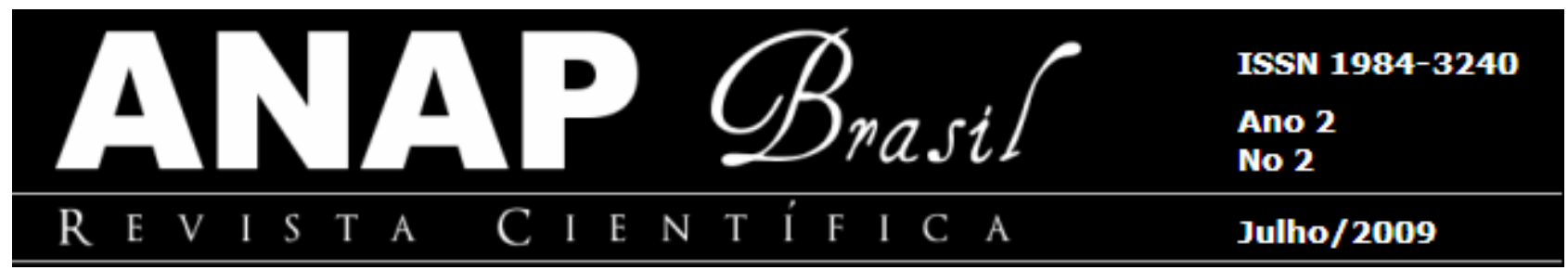

sociedade. Observa-se, então que o pensamento se imbrica com o PARADIGMA, e, antes de conceituar "Paradigma" é importante explicitar qual o sentido de pensamento para Edgar Morin: "Para ele, pensar é pensar em movimento. O processo de pensamento é um processo dinâmico de construção" (ROGER, 1999, p.90).

Para entender melhor, tem-se o Paradigma de Complexidade e o Paradigma de Simplificação, em ambos os casos se usa a lógica para refletir os problemas. Na complexidade, pensa-se em movimento aquilo que a lógica clássica (Reducionismo) pensa de maneira estática. Para pensar complexamente, precisamos mudar crenças básicas: em vez de acreditar que vamos ter como objeto de estudo o elemento, ou o indivíduo, e que teremos de delimitá-lo muito bem, precisamos passar a acreditar que estudaremos ou trabalharemos sempre com o objeto em contexto.

Contextualizar é reintegrar o objeto no contexto, ou seja, é vê-lo existindo no sistema. É colocar o foco nas inter-relações, assim ver-se-á esse sistema interagindo com outros sistemas, uma rede de padrões interconectados, conexões ecossistêmicas, redes de redes ou sistemas de sistemas. Colocar o foco nas relações não faz desaparecer os elementos que se relacionam. Ver figura:

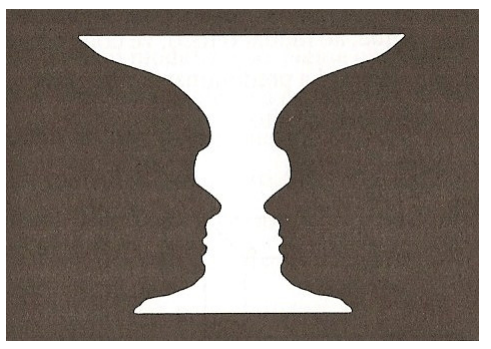

Fonte: VASCONCELLOS, 2002, p. 112

\section{PARADIGMA}

Voltando-se ao PARADIGMA, tem-se que esse termo tem sido usado para se referir à forma como percebemos e atuamos no mundo, ou seja, às nossas regras de ver o mundo. Vem do grego PARÁDEIGMA que significa modelo, padrão (Vasconcellos, 2002, p. 30). Paradigmas, de certa forma, correspondem a expectativas. Os paradigmas influem em nossas percepções, em nossas ações fazendo-nos acreditar que o jeito como fazemos as coisas é o certo ou a única forma de fazer. 


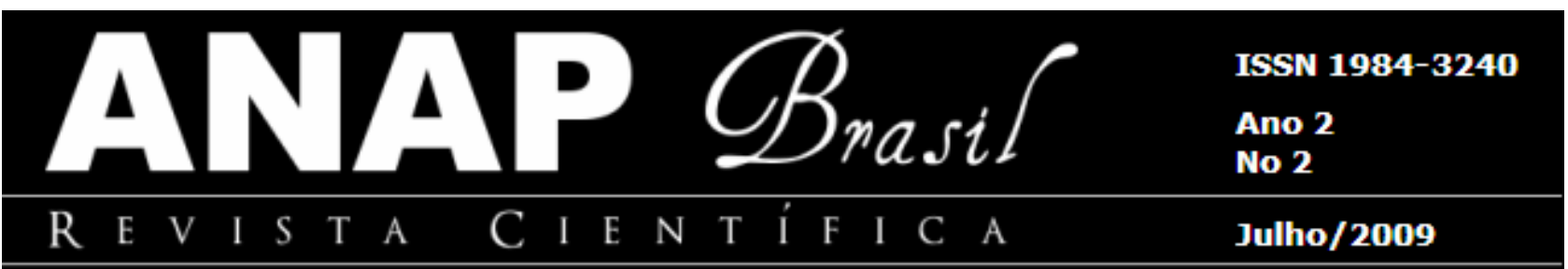

Assim, costumam impedir-nos de aceitar idéias novas, tornando-nos pouco flexíveis e resistentes a mudanças. Uma pergunta que pode ajudar-nos a perceber os limites do nosso atual paradigma: O que hoje me parece impossível fazer, mas que, se fosse feito, mudaria radicalmente as coisas?

O que hoje nos parece impossível pode se tornar o padrão amanhã. Nossos antepassados lidaram com profundas mudanças de paradigmas, à medida que foram surgindo o rádio, o cinema, o avião e tantas outras novidades. Também nós temos capacidade de criar e lidar com mudanças de paradigmas, termo que pode se referir, ainda, ao conjunto de crenças e valores subjacentes à prática científica.

Para Morin, os paradigmas são princípios supra lógicos de organização do pensamento, princípios ocultos que governam nossa visão de mundo, que controlam a lógica de nosso discurso, que comandam nossa seleção de dados significativos e nossa recusa dos não-significativos, sem que tenhamos consciência disso.

No paradigma tradicional da Ciência, nossa tendência é procurar uma causa para o fenômeno que observamos no contexto de uma causalidade linear, localizando em um ponto da seqüência de interações a causa do que está acontecendo.

No entanto, ao se ampliar o foco da observação, está-se tentando se aproximar da complexidade da questão. Pode-se perceber em que circunstâncias o fenômeno acontece, ver-se-á relações intra-sistêmica e inter-sistêmicas; É possível perceber não mais um fenômeno, mas uma teia de fenômenos recursivamente interligados e, portanto, ter-se-á diante de si a complexidade do sistema. Assim sendo, pode-se considerar o pensamento sistêmico como um novo paradigma da Ciência, trata-se de um novo ou renovado modo de pensar.

Capra coloca que o pensamento sistêmico pode ser um pensamento contextual e ao mesmo tempo processual, ou seja, detecta-se o dinamismo, o movimento e que busca a articulação em vez da disjunção. Chega-se, então, ao método.

\section{MÉTODO}

O método é um instrumento do conhecimento que proporciona aos pesquisadores, em qualquer área de sua formação, orientação geral que facilita planejar uma pesquisa, 


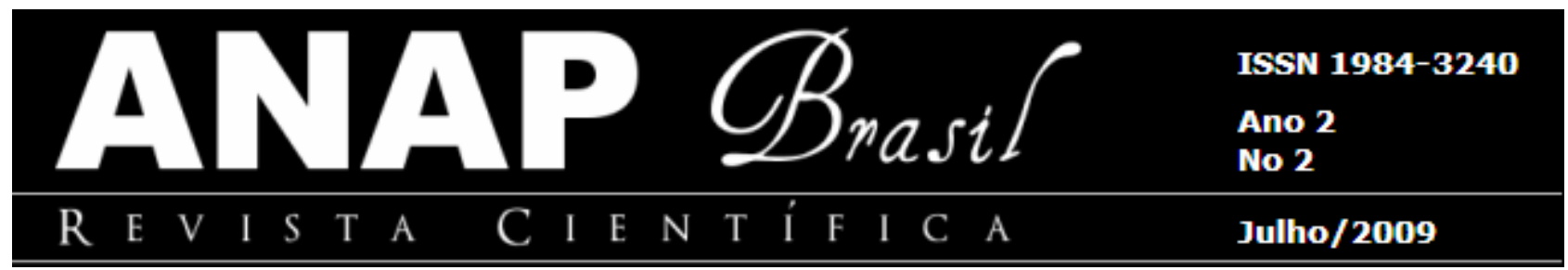

formular hipóteses, coordenar investigações, realizar experiências e interpretar. Também se admite que um Método em pesquisas, seja qual for o seu tipo, é a escolha de procedimentos sistemáticos para descrição e explicação do estudo.

O método cartesiano (reducionista) obedece a um princípio de ordem (eliminando a desordem), de claridade (eliminando o obscuro), de distinção (eliminando participações e comunicações), de disjunção (eliminando o sujeito, a complexidade), ou seja, deve obedecer a um princípio que liga a Ciência à simplificação lógica.

Já o método que se coloca no pensamento complexo é, ao contrário, o de ligar o que estava separado através de um princípio de complexidade. O método do pensamento complexo não é uma camisa de força. Mas sim, a arte de religar o que a análise desagrega, de contextualizar quando o reducionismo separa, de historiar o método, os conceitos e o sujeito pensante, para não ser governado - ou sê-lo o mínimo possível pelo idealismo da simplificação ou da abstração.

E, afinal, o que é complexidade?

Há diferentes conceituações para o termo complexidade. Etimologicamente tem:

Origem no Latim complexus, ou seja, o que está tecido em conjunto, como numa tapeçaria. Refere-se a um conjunto, cujos constituintes heterogêneos estão inseparavelmente associados e integrados, sendo ao mesmo tempo uno e múltiplo (VASCONCELLOS, 2002, p.110).

Logo, pensar sistemicamente é pensar a complexidade, a instabilidade e a intersubjetividade. Ou seja, a complexidade, a instabilidade e a intersubjetividade constituem em conjunto uma visão de mundo sistêmica;

Dessa forma, segue-se uma reflexão: todo ser vivo é um organismo eminentemente complexo, uma testemunha de um longo processo de complexificação, do qual o cérebro do homem é o mais belo exemplo. A complexidade resulta de uma dinâmica da evolução do Universo e da vida. Ela é conseqüência daquilo que caracteriza a vida: a diversidade. Ela está diante de nós, como o infinito, e ainda assim a ignoramos. Ignorar a complexidade não é o mesmo que ignorar a vida?

\section{GEOGRAFIA DA COMPLEXIDADE}




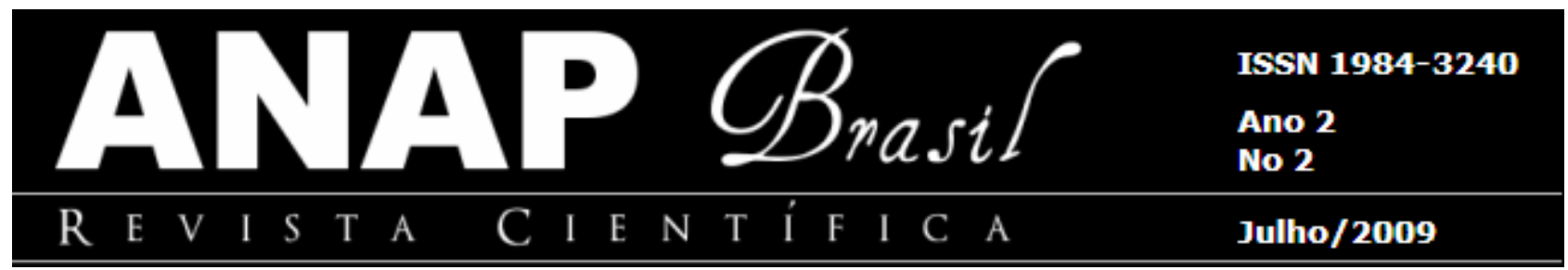

"Freud, em um de seus trabalhos, afirma que um dos enigmas fundamentais da vida diz respeito à questão da relação do homem com o espaço" (SILVA; GALENO, 2004. p.7).

Hoje há certo consenso de que a Geografia não é ciência da mera descrição fria dos elementos terrestres ou somente coordenadas que servem de orientação ao homem. A Geografia deve ter por objetivo uma obra aberta que é o homem num planeta de encantamento misterioso e incerto.

Por sua vez, Edgar Morin apud (SUERTEGARAY, 2004), identifica na Geografia a presença de um conhecimento multidimensional e formador de uma epistemologia da complexidade por princípio, haja vista abranger desde a física terrestre, a biosfera e as implantações humanas.

Sabe-se que a Geografia, desde sua origem como campo de conhecimento e, mesmo antes, desde a Antiguidade, sempre se preocupou em compreender o espaço geográfico, ou melhor, o espaço "morada do homem".

Em princípio, o que se entende por espaço geográfico? Nada mais do que a materialização das práticas humanas sobre a superfície da Terra.

A Geografia, então, trata de refletir sobre a produção do espaço na sua relação complexa e contraditória entre as práticas humanas que decorrem de seu modo de produzir, de sua forma de se organizar socialmente e da construção de sua cultura. Pensando-se dessa forma, o espaço geográfico constitui uma totalidade impossível de ser contemplada analiticamente.

Por essa razão, esse espaço é lido a partir de diferentes conceitos, que são expressões diferenciadas da leitura geográfica sobre o espaço geográfico, tais como: ambiente, domínio, paisagem, região, território, geossistemas, redes, lugar.

Hoje, a Geografia talvez seja o saber que mais vivencia a experiência de poder tecer um conhecimento ancorado na interface dos outros saberes, mesmo que tenha negligenciado uma formulação epistemológica consistente sobre isso. Perdida em querer se reconhecer como ciência a partir de um modelo padrão que separa e fragmenta a compreensão do mundo em nome de um objeto, a Geografia deixa de reconhecer e explorar epistemologicamente o que lhe é mais sagrado, que é conhecer, a partir da religação dos saberes, o mundo simultaneamente real e virtual, concreto e imaginário, natural e cultural. Mesmo com essa lacuna epistemológica, é possível percorrer itinerários, refazer percursos, religar linguagens para reorganizar sentidos e comungar idéias (DANTAS, 2004, p. 238). 


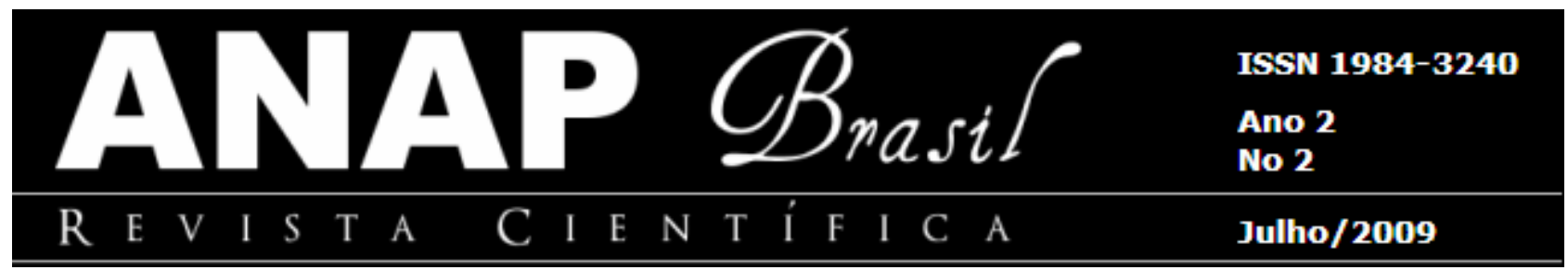

Surge a Teoria Sistêmica, cujo responsável por sua divulgação foi o biólogo alemão Bertalanffy nos anos trinta do século vinte e difundida nos anos cinqüenta do mesmo século, a qual permitiu a Geografia entender os fenômenos através de uma maior integração entre os elementos que os compõem.

Porém, dificuldades metodológicas de aplicação dessa teoria na Geografia geraram a necessidade de se incluir outras formas de pensar e, nesse contexto, inclui-se a Teoria da Complexidade. Assim, a Teoria da Complexidade aplicada à Geografia por meio da abordagem sistêmica, pode auxiliar o desenvolvimento de seus estudos por proporcionar uma visão da emergência dos atributos, gerados através da interligação das partes que compõe o "todo" e, que para a Geografia é a organização do espaço.

$\mathrm{Na}$ Geografia o conceito de complexidade aparece mais substancialmente a partir da década de 1960, através de trabalhos que abordam a necessidade de compreensão da organização espacial. Não existe mais uma maneira de se tratar o homem sem considerar um espaço geográfico, nem mesmo se referir a um ambiente físico sem relacioná-lo a uma intervenção antrópica, por menor que seja, é consenso que as diferentes escalas e esferas sejam interligadas.

A Geografia, então, para poder compreender a organização do espaço, tem na abordagem sistêmica e na teoria da complexidade um arcabouço teórico e metodológico para a otimização dos seus estudos, pois a partir delas busca explicar os processos naturais e humanos que dinamizam os geossistemas, unidade de análise que tem respaldo em nomes como Sotchava ; Bertrand; Tricart e Monteiro, este último brasileiro.

O termo geossistema possui duas predominantes vertentes de definição: uma russa e outra francesa. Segundo Sotchava (russo):

Os geossistemas são uma classe peculiar de sistemas dinâmicos abertos e hierarquicamente organizados, de acordo com a definição de Bertalanffy. Assim, tanto uma área elementar da superfície da Terra como o geossistema planetário, ou as subdivisões intermediárias do meio natural, representam uma unidade dinâmica, com uma organização geográfica a ela inerente (ROSS, 2006, p.24).

Para Bertrand (francês), apoiado em outros pensadores inclusive Tansley da Ecologia aborda os geossistemas sob a luz da "paisagem ecológica". As paisagens são 


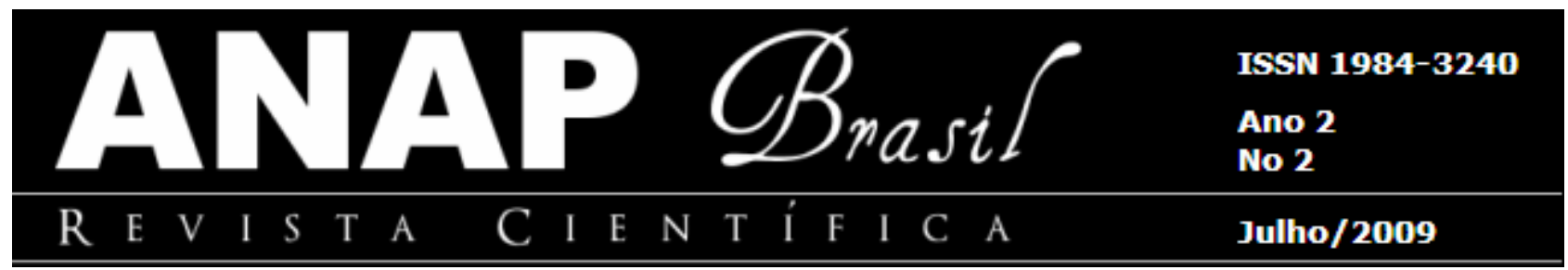

individualizadas em ecótopos, que são unidades comparáveis a ecossistemas, em que se reagrupam todos os elementos da paisagem, inclusive os de origem antrópica. Logo: "para Bertrand, o geossistema corresponde a uma paisagem nítida e bem circunscrita que se pode, por exemplo, identificar instantaneamente nas fotografias aéreas" (ROSS, 2006, p.30).

Ressalta-se, no entanto, que desde longa data a Geografia, mesmo inconscientemente já desenvolvia estudos complexos. Exemplos: Ratzel, La Blache, Reclus.

De acordo com Carvalho (2006, p. 72-74), Ratzel deixou claro em sua obra tornada pública entre os anos de 1882-1902, que o objetivo da Geografia seria "argumentar e demonstrar as conexões existentes entre todas as coisas presentes na Terra", por acreditar que a mesma se constituía em um único complexo. Como propôs um método organicista numa época em que todos buscavam a separação do conhecimento foi criticado duramente pelos demais pesquisadores.

Por sua vez, La Blache, no âmbito da Geografia Física, argumenta que a Geografia deve tratar da "combinação dos fenômenos". E que "não se pode isolar nenhuma parte, pois cada uma age sobre sua vizinha". Ele coloca, ainda,que:

A geografia tem, pois, diante dela, um belo e difícil problema, o de compreender, no conjunto dos caracteres que compõem a fisionomia de uma região, o encadeamento, uma expressão das leis gerais do organismo terrestre. Problema que é necessário, a cada dia, reconhecer e cuja complexidade é essencial aumentar, isso porque nós portamos exig encias de análise mais exatas e percebemos cada vez mais a intervenção de causas que remontam a um passado longíquo, no estado da Terra (SILVA, 2006, p.137).

Elisée Reclus, por sua vez, fala sobre os vários componentes que se interagem para determinar tanto a organização do espaço quanto a maneira de ser das comunidades em vários locais do mundo, afirmando que os aspectos naturais, através de suas interrelações, se inter-relacionam com os aspectos sociais, num sistema complexo.

Um sistema complexo pode ser definido como sendo composto por grande quantidade de componentes interatuantes, capazes de trocar informações com seu entorno e capazes, também, de adaptar sua estrutura interna como conseqüências ligadas a tais interações. 


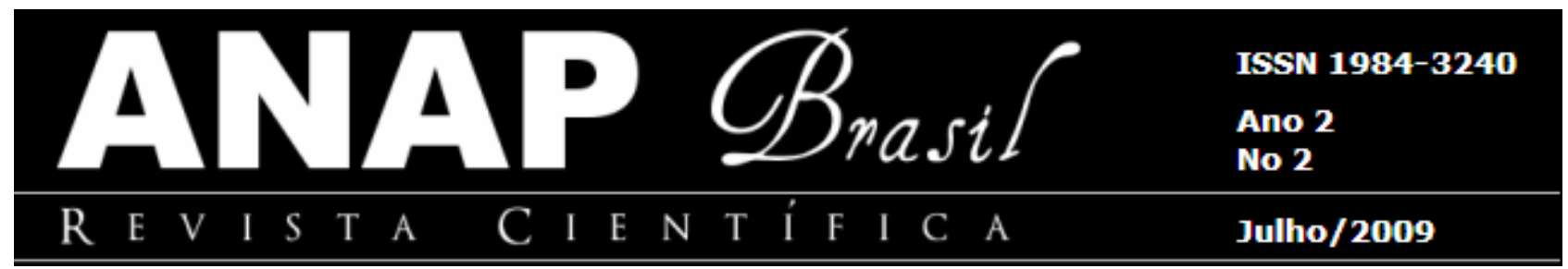

O desenvolvimento da informática e dos programas computacionais vem favorecendo o estudo dos sistemas complexos. Considerando-se a Terra como um geossistema, podese afirmar que qualquer alteração em seus componentes que ultrapassar seus limites de resistência, pode desestabilizá-la e levá-la a uma readaptação para um novo estado de equilíbrio. $O$ enfoque pode ser no âmbito dos impactos ambientais e na relação sócioeconômica também.

Além de que, este flanco da ciência geográfica ainda encontra-se em plena formação tanto epistemológica, quanto metodológica. Lembrando que Geografia também é arte:

O ser, singular ou coletivo, que vive em harmonia com seu território, desenha contornos de uma geografia poética. O ser feliz é sem dúvida aquele que, como a criança, aqui e agora, se entrega a uma leitura inventiva das formas familiares e quotidianas de seu jardim, para metamorfoseá-las em um mundo novo, domesticado onde tudo se transforma sem, no entanto, jamais se revelar totalmente (ROUX, 2006, p.42).

Em Almeida; Carvalho (2002, p.69), encontra-se a seguinte mensagem:

Como Platão o disse há muito tempo: para ensinar é preciso o Eros. O Eros não é somente o desejo de conhecer e transmitir, ou somente, o prazer de ensinar, comunicar ou dar; é também o amor por aquilo que se diz e do que se pensa ser verdadeiro. É o amor que introduz a profissão pedagógica, a verdadeira missão do educador.

\section{CONCLUSÃO}

Conclui-se que a Geografia possa ter um papel importante ao compreender os mecanismos atuantes no espaço: poderá organizá-lo e planejá-lo de forma mais adequada.

Acredita-se, ainda, que se está contribuindo para uma melhor performance de um geógrafo, professor ou bacharel, ao se expor um pouco da vida de um grande pensador como Edgar Morin e perceber como a complexidade foi se aproximando de sua vida, de seu trabalho e incluindo a sensibilidade, o amor, a ética entre outros valores individuais e 


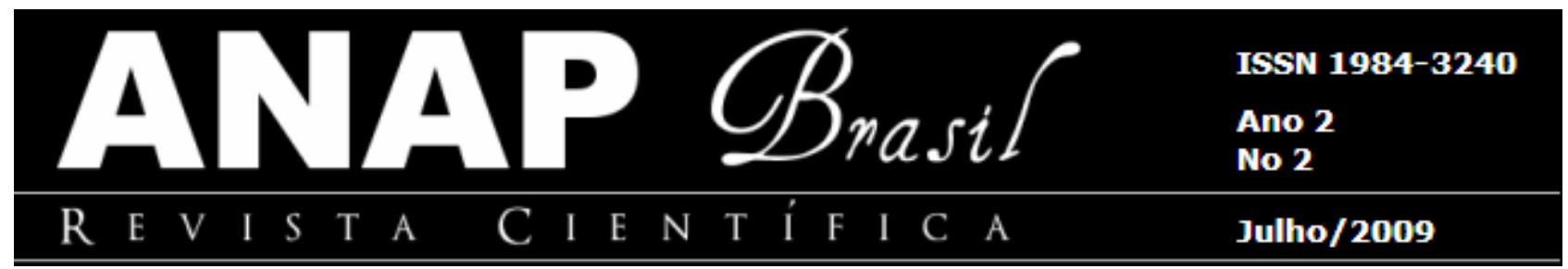

coletivos que cada lugar e cada sociedade expõe e influencia a vida de cada cidadão. A Geografia, como outras ciências, enxerga no pensamento complexo uma nova oportunidade de trabalhar a mãe Terra interligando seus fenômenos, físicos e humanos que se entrelaçam fornecendo ao mundo um entendimento mais harmonioso e fundamental para as expectativas ambientais que cada vez mais se avolumam em busca de soluções.

\section{REFERÊNCIAS}

Foto de Edgar Morin disponível em:< file://K:lEdgar Morin lfoto edgar morin 2.mht>. Acesso em 24 set. 2008.

CHAUÍ, Marilena. Convite á filosofia. 12 ed. São Paulo: Ática, 2002.

DANTAS, Eugênia Maria. Caminhos de uma geografia complexa. In: SILVA, Aldo Aloísio Dantas da; GALENO, Alex (Orgs.). Geografia: ciência do complexus: ensaios transdisciplinares. Porto Alegre: Sulina, 2004.

GENTILE, Paola. Fala mestre! Edgar Morin: a escola mata a curiosidade. Nova escola on-line - o site de quem educa. Índice da edição 168, dez. 2003. Disponível em:http://revistaescola.abril.com.br/preview.shtml. Acesso em: 24 set. 2008.

KÖCHE, José Carlos. Fundamentos de metodologia científica. Petrópolis, RJ: Vozes, 1997.

LAKATOS, Eva Maria; MARCONI, Marina de Andrade. Fundamentos de metodologia científica. 5 ed. São Paulo: Atlas, 2003.

MORIN, Edgar. A cabeça bem-feita: repensar a reforma, reformar o pensamento. Tradução de Eloá Jacobina. 4 ed. Rio de Janeiro: Bertrand Brasil, 2001.

.; ALMEIDA, Maria da Conceição de.; CARVALHO, Edgar de Assis (Orgs.).

Educação e complexidade: os sete saberes e outros ensaios. Tradução de Edgar de Assis Carvalho. São Paulo: Cortez, 2002.

. O método 1: a natureza da natureza. 2 ed. Tradução de llana Heinberg. Porto Alegre: Sulina, 2003.

PENA-VEGA, Alfredo; ALMEIDA, Elimar Pinheiro de (Orgs.). O pensar complexo: Edgar Morin e a crise da modernidade. Rio de Janeiro: Garamond, 1999. 


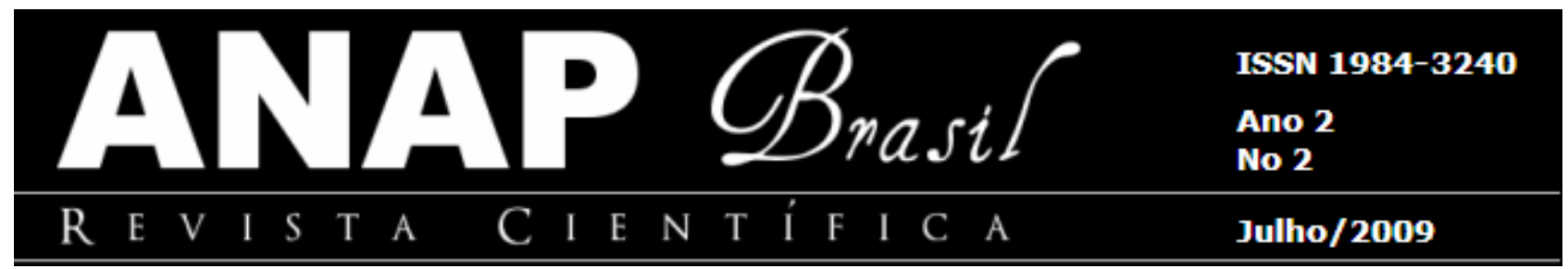

ROGER, Emilio. Uma antropologia complexa para entrar no século XXI. In: PENA-VEGA, Alfredo; ALMEIDA, Elimar Pinheiro de (Orgs.). 0 pensar complexo: Edgar Morin e a crise da modernidade. Rio de Janeiro: Garamond, 1999.

ROSS, Jurandir. Ecogeografia do Brasil: subsídios para planejamento ambiental. São Paulo: Oficina de Textos, 2006.

ROUX, Michel. O re-encantamento do territótio (o território nos rastros da complexidade). In: SILVA, Aldo Aloísio Dantas da; GALENO, Alex (Orgs.). Geografia: ciência do complexus: ensaios transdisciplinares. Porto Alegre: Sulina, 2004.

SESC - Serviço Social do Comércio. Biografia de Edgar Morin. Disponível em:http://edgarmorin.sescsp.org.br. Acesso em: 27 set. 2008.

SILVA, Aldo Aloísio Dantas da; GALENO, Alex (Orgs.). Geografia: ciência do complexus: ensaios transdisciplinares. Porto Alegre: Sulina, 2004.

SILVA, Aldo Aloísio Dantas da. A idéia de conexidade em Vidal de La Blache. In: SILVA, Aldo Aloísio Dantas da; GALENO, Alex (Orgs.). Geografia: ciência do complexus: ensaios transdisciplinares. Porto Alegre: Sulina, 2004.

SUERTEGARAY, Dirce Maria Antunes. Ambiência e pensamento complexo: resignific(ação) da geografia. In: SILVA, Aldo Aloísio Dantas da; GALENO, Alex (Orgs.). Geografia: ciência do complexus: ensaios transdisciplinares. Porto Alegre: Sulina, 2004.

UNINOVE (Universidade Nove de Julho). Obras de Edgar Morin. Disponível em: http://www4.uninove.br/grupec/BioObras.htm. Acesso em: 27 set. 2008.

Vasconcellos, Maria José Esteves de. Pensamento sistêmico: o novo paradigma da ciência. Campinas,SP: Papirus, 2002. 